Publicación semestral. ISSN 2215-4906

Volumen 81 - Número 1 Julio - Diciembre 2021

\title{
COMUNIDANZA II: análisis en torno a la práctica artística entre danza, comunidades y acción social
}

\author{
COMUNIDANZA Il: Analysis on the Artistic Practice Between \\ Dance, Communities and Social Action
}

Verónica Monestel Chaves

DOI 10.15517/es.v81i1.47651

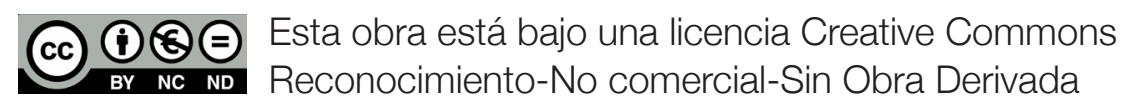


Dossier

\title{
COMUNIDANZA II: análisis en torno a la práctica artística entre danza, comunidades y acción social
}

\section{COMUNIDANZA II: Analysis on the Artistic Practice Between Dance, Communities and Social Action}

\author{
Verónica Monestel Chaves ${ }^{1}$ \\ Universidad de Costa Rica \\ San José, Costa Rica
}

Recibido: 12 de febrero de 2021

Aprobado: 19 de marzo de 2021

\section{Resumen:}

Este artículo parte del proceso de sistematización del proyecto Comunidanza Il: análisis en torno a la práctica artística entre danza,comunidades y acción social, propuesto para la compañía de danza de la Universidad de Costa Rica Danza Universitaria, en el año 2020. El mismo tiene como objetivo la visibilización, análisis y re-conceptualización de la acción social a partir de las prácticas artísticas comunitarias realizadas por la agrupación entre el 2011-2019. Se propone una escucha anticipada de carácter lúdico y creativo, centrada en la acción, la construcción de nuevas metodologías de mediación y el desarrollo comunitario inclusivo y descentralizado. Los vínculos en la acción comunitaria, el cuerpo, la naturaleza interactiva de la danza y su componente educativo se identifican como ejes fundacionales implícitos en su práctica. La reflexión se nutre del campo de la sociología, el arte comunitario, la antropología filosófica, la psicología y la educación.

Palabras clave: acción social; danza; comunicación; comunidad; cuerpo; interacción social; práctica artística; vínculo

1 Bailarina-intérprete e investigadora de Danza Universitaria, Universidad de Costa Rica. Bachiller internacional en Danza-Performance por la Hoogeschool vor de Kunste Arhnem. Cursa el Bachillerato en Psicopedagogía en la Universidad Autónoma de Centroamérica. ORCID: 0000-00027305-5489. Correo electrónico: veronica.monestel@ucr.ac.cr 


\begin{abstract}
:
This paper is part of the systematization process of the Comunidanza II project: analysis on the artistic practice between dance, communities and social action, proposed to the dance company of the Universidad de Costa Rica-Danza Universitaria, in 2020. It aims at the visibility, analysis and re-conceptualization of social action based on the community artistic practices carried out by the group between 2011-2019. It proposes a playful and creative early listening, focused on action, the construction of new mediation methodologies and inclusive and decentralized community development. The links in community action, the body, the interactive nature of dance and its educational component are identified as foundational axes implicit in its practice. Reflection draws on the field of sociology, community art, philosophical anthropology; as well as psychology and education.
\end{abstract}

Keywords: social action; dance; communication; community; body; social interaction; artistic practice; bond 
COMUNIDANZA II: análisis en torno a la práctica artística entre danza,

Dossier comunidades y acción social

\section{Introducción}

Si el accionar de la danza apela a un encuentro con el mundo y con otras corporalidades, si impulsa un movimiento de fuerzas desde lo táctil que problematiza lo real en el escenario y en los espacios que ha decidido reconfigurar desde la construcción de otras relaciones y geografías de acción, entonces, la danza habita ese cruce entre el arte y lo político (Macias, 2009, p. 130).

Este documento se elaboró durante el periodo 2020-2021. El mismo se basa en el trabajo realizado por Danza Universitaria entre los años 2011-2019 y tiene como objetivo la visibilización y el análisis del trabajo dancístico en comunidades; además, parte de la experiencia de la agrupación adquirida a lo largo de 42 años de existencia. Cabe indicar que en este lapso, ocho años han sido dedicados a prácticas artísticas comunitarias con el respaldo de la Universidad de Costa Rica, así como de diferentes organizaciones, grupos docentes y estudiantiles, municipalidades, centros educativos, gremios de la danza y población civil. A partir de las vinculaciones construidas, se han desarrollado experiencias en, para y con el cuerpo y el movimiento, donde la práctica artística se hace camino con los saberes comunitarios.

La investigación se llevó a cabo a partir de estrategias virtuales incorporadas en el contexto de la pandemia por COVID-19. Para ello se utilizó material del archivo de Danza Universitaria (videos, fotografías, libros, informes y propuestas de proyectos) que, en conjunto, establecen un marco general de información para el análisis de las acciones comunitarias llevadas a cabo en el período 2011-2019. Se seleccionaron nueve proyectos en áreas como: la creación artística, la mediación educativa, las charlas, las conferencias y la experiencia de la propuesta de carrera en Danza y Corporeidad, para conocer el criterio de los profesionales de la agrupación sobre algunos conceptos. Estos, posteriormente, fueron utilizados para el análisis y se aplicaron dos cuestionarios en categorías específicas.

A partir de ello se espera que la práctica artística en danza sea un epicentro del hacer-acción, vista como potenciadora de cambio. Así mismo, se anhela que la comunicación, el vínculo, la interacción social y los procesos continuos de aprendizaje sean vistos como constantes necesarias en la experiencia de un sujeto en movimiento-corposintiente y pensante, dueño de un saber del cuerpo que abre espacio a su propia transformación y a la colectiva.

ESCENA. Revista de las artes, 2021, Vol. 81, Núm. 1 (julio-diciembre), pp. 369-398 


\section{Danza Universitaria: antecedentes 2011-2019}

Con la fundación de Danza Universitaria (DU), en el año 1978, inicia la difusión de la danza contemporánea en Costa Rica. La extensión cultural da sus primeros pasos en la Vicerrectoría de Acción Social gracias a la visión e interés de la antropóloga María Eugenia Bozzoli Vargas, quien acoge a DU como la primera compañía profesional de danza en el país (Ávila, 2008).

La relación con las comunidades inicia a través de la solicitud de espectáculos en escuelas, gimnasios, hospitales psiquiátricos, salones comunales, casas de la cultura y universidades. En ese momento se realizaban visitas a Puntarenas, Guanacaste, Palmar Sur, Limón y a otras comunidades de la capital. La difusión de espectáculos fue un enfoque importante para el desarrollo del elenco y una oportunidad para el entonces director, Rogelio López, de relacionarse con el público a partir de conversatorios informales. López describía la dinámica artística con base en clases técnicas y ensayos profesionales. De esta forma, DU fomentó un tipo de relación con algunos sectores y logró una difusión y descentralización de espectáculos que permitiera el acceso de otros públicos a la danza.

En relación con lo anterior, la experiencia corporal busca espacios de descentralización del conocimiento, así como iniciativas de arte y prácticas artísticas comunitarias, en donde el intercambio de saberes suceda como una experiencia colectiva e integrada para todos los involucrados. La propuesta de carrera en Danza y Corporeidad, elaborada durante los últimos siete años, describe parte de esa visión:

La evolución de la compañía ha implicado la ampliación de su quehacer, además de obras escénicas colectivas, se incluyen proyectos comunitarios (Comunidanza, Juventud Creativa, Talleres de Movimiento en comunidad) en busca de la descentralización y democratización de la danza contemporánea y en la posibilidad de generar conocimiento a partir de una experiencia dialógica con grupos y poblaciones (Universidad de Costa Rica, 2019a, p. 8).

Las propuestas en danza realizadas entre los años 2011-2019 promueven la docencia, la investigación y la acción social como ejes transversales de instituciones, intencionados desde el arte del movimiento, el lenguaje del cuerpo y las demandas existentes. La participación de menores, adolescentes y adultos ha creado nuevas relaciones mediante talleres, espectáculos, clases maestras, charlas y capacitaciones. Se ha tratado de implementar 
COMUNIDANZA II: análisis en torno a la práctica artística entre danza,

Dossier comunidades y acción social

de manera sistemática un marco de referencia acorde con los propósitos ${ }^{2}$ y políticas institucionales ${ }^{3}$ que complementan, comparten y propician el trabajo artístico, pero, sobretodo, se ha buscado dar un lugar a la danza como acción fundacional de múltiples acciones.

\section{Ruta histórica comunitaria 2011-2019}

El poder de la práctica artística y sus manifestaciones expresivas logran complementar intereses individuales y colectivos dentro de las comunidades. A través de las posibilidades del arte, la comunidad encuentra un discurso y trabaja en su propio desarrollo humano mediante proyectos que permiten otra interpretación de la realidad.

La incorporación de la danza como práctica artística suma procesos comunitarios diversos, desde, con y en el lenguaje del cuerpo y su expresividad. Se comparte como una práctica que va más allá de las formas tradicionales del arte erudito, como una manifestación socio-cultural que levanta la voz de cuerpos expresivos, con enunciados políticos, estéticos, psicológicos y sociales, en el contexto de grupos, poblaciones y organizaciones particulares.

Este tipo de experiencias se analizan a partir de una recopilación de proyectos que muestran los diferentes espacios de acción construidos por DU entre el periodo 2011-2019. Los proyectos se detallan a continuación.

\section{Comunidanza I: Turrialba, Limón, Tilarán, Liberia, Monteverde (2011-2012)}

"Comunidanza"4, el primer documental que realizó DU en torno a las prácticas comunitarias, fue efectuado por Verónica Monestel y Giuseppe Cirotti en el periodo 20112012. Este tiempo sirvió para pensar la participación artística y docente de la compañía en comunidades fuera del Gran Área Metropolitana (GAM). La participación de todo el elenco durante los talleres realizados introdujo la asignación de nuevas responsabilidades y roles que generaron a la vez inéditas experiencias profesionales, además de las presentaciones artísticas regulares (Danza Universitaria, s.f., "Comunidanza").

2 Para conocer los propósitos de la Universidad de Costa Rica (UCR), consultar el Estatuto Orgánico de la Universidad de Costa Rica (Universidad de Costa Rica, 2005).

3 Ver los ejes: I-II-IV-VII-VIII de las Políticas Institucionales 2021-2025 (Universidad de Costa Rica, 2015).

4 Este documental (Cirotti, Camacho \& Monestel, 2012) está disponible en https://vimeo. com/55070443

ESCENA. Revista de las artes, 2021, Vol. 81, Núm. 1 (julio-diciembre), pp. 369-398 
Durante este proceso no solo se visibilizó el trabajo de la compañía y su forma de organizar y llevar espectáculos a la comunidad, sino que se pudieron recopilar testimonios de las personas participantes en los talleres: el público y los coordinadores culturales de las zonas. De esta forma, se conocieron parte de las necesidades y las demandas de las poblaciones, las cuales exigían más actividades, experiencias y procesos artísticos de mayor duración. El proyecto documental Comunidanza I (Imagen 1) se establece como punto de partida y de quiebre en el trabajo artístico comunitario de DU.

Imagen 1. Filmación proyecto Comunidanza. Taller Protegido de Alajuela

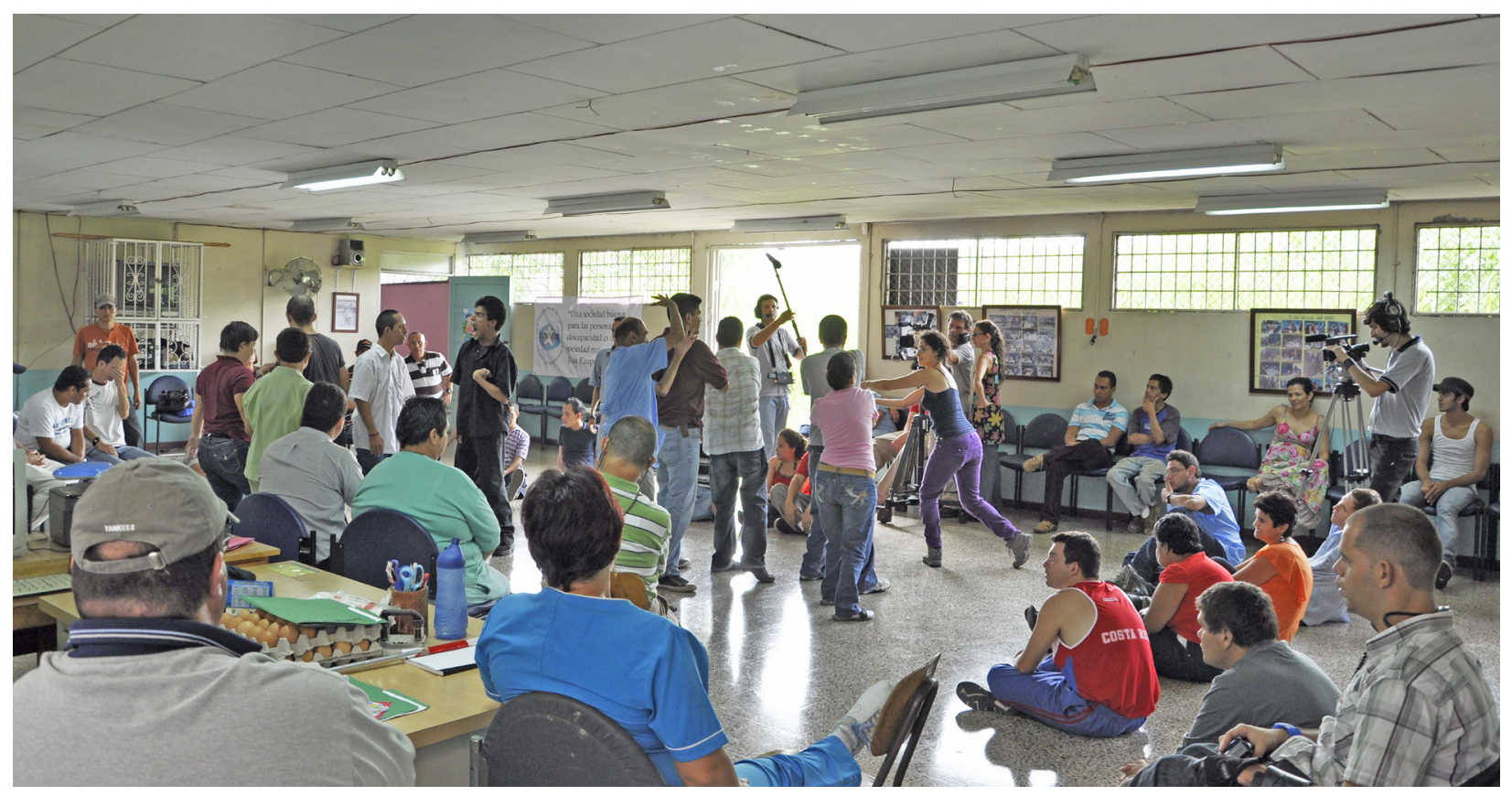

Fuente: Archivo Danza Universitaria (2011).

Como consecuencia de estas demandas, DU participó en el año 2013 de los Fondos Concursables organizados por la Vicerrectoría de Acción Social de la Universidad de Costa Rica, con el proyecto: "Talleres de Movimiento en Comunidades". En este, los miembros de la compañía se trasladaron a otras áreas del país por un tiempo más prolongado, a partir de una estrategia previa con la comunidad.

Un antecedente importante de estos procesos se dio en la década de los años noventa con el proyecto piloto de las bailarinas Virginia Cortez, Ena Aguilar e Ivón Durán, quienes se trasladaron a la provincia de Limón, durante varios fines de semana, con el 
objetivo de trabajar junto a comparsas, cuadrillas, trabajadores de muelles, colegiales y población en general. El proyecto se extendió por un año. En este intervalo, cada una de las bailarinas trabajaba con un grupo distinto cada fin de semana. Su trabajo incluía una clase de danza de nivel básico, con acondicionamiento físico, variaciones de movimiento e improvisación. Los altos del Museo de la Ciudad de Limón era el espacio de acción. El trío de bailarinas presentó su trabajo en muchos lugares, entre ellos Turrialba, San Ramón, Guápiles, Barva de Heredia, Quepos, Liberia, San Isidro del General y Plaza de la Cultura. También realizaron presentaciones en instituciones como la Escuela Centeno Güell y en empresas privadas. Además, se montaron trabajos de movimiento en la Sede Rodrigo Facio como un espectáculo de clausura.

Sin embargo, este fue uno de los pocos proyectos realizados en DU con una intención comunitaria. Por muchos años, las actividades de carácter docente estaban a cargo únicamente de la dirección. El elenco no tenía participación docente, su labor giró en torno a la presentación de los espectáculos y su rol de intérpretes.

\section{Juventud Creativa (2011)}

El proyecto piloto "Juventud Creativa" (2011) se realizó en el Colegio Vargas Calvo en San Pedro de Montes de Oca. Este fue coordinado por Evelyn Ureña, Iván Saballos, Eduardo Guerra y Elián López. Además, constituyó un primer paso importante de DU por generar un acercamiento formal con instituciones públicas responsables de la educación de jóvenes costarricenses en ambientes de violencia, deserción escolar, situaciones de riesgo tales como problemáticas relacionadas con drogas, alcohol, sexualidad irresponsable y abusos (Danza Universitaria, s.f., "Juventud Creativa").

El objetivo fue aportar al desarrollo integral del joven adolescente con talleres de movimiento y experimentación del cuerpo, para así despertar sus inquietudes artísticas, de autoconciencia y visión del entorno de su comunidad. Se trabajó con ellos por más de diez meses. De este lapso, cinco meses se dedicaron a la realización de talleres, así como al montaje de la obra El Aparato, un espectáculo basado en dinámicas y temas utilizados en los talleres, los cuales estaban íntimamente ligados a la metodología aplicada. Participaron estudiantes de diferentes niveles de la institución y se presentaron en el Teatro Montes de Oca de la Universidad de Costa Rica. Cabe resaltar que en este proyecto se logró una importante articulación interinstitucional entre Municipalidad, barrios, centros culturales y la comunidad educativa, la cual ayudó a identificar debilidades y fortalezas comunitarias 
a nivel interno y externo. En el año 2014, se retoma el proyecto a través de una sistematización de experiencias que reconstruye el proceso y visibiliza las estrategias metodológicas de los profesionales. Sobre este documento se hablará particularmente más adelante.

\section{Danza a la Carta (2011)}

"Danza a la carta” es una iniciativa interesada en la generación de públicos, dirigida a la comunidad estudiantil de centros educativos aledaños al cantón de Montes de Oca. El proyecto tomó en cuenta la participación de artistas independientes, quienes presentaron sus espectáculos con el apoyo de la Municipalidad de Montes de Oca y Danza Universitaria.

Uno de los aspectos más relevantes de esta iniciativa fue beneficiar a las poblaciones, por cuanto promovió, de manera didáctica, la sensibilización y la formación de público estudiantil con pocas oportunidades de acceder espacios artísticos. "Danza a la Carta" se realizó cada martes al mediodía en el Teatro Montes de Oca de la Universidad de Costa Rica. Los diferentes centros educativos de la comunidad podían apreciar a los artistas y tenían la oportunidad de conversar con ellos mediante preguntas e intercambio de impresiones. Este proceso generó también la sistematización "Danza a la carta: un menú para la comunidad" en el 2014 (Danza Universitaria, s.f., "Danza a la carta").

\section{Fondos Concursables- Talleres de Movimiento (2013)}

Los Fondos Concursables fueron una plataforma para el proyecto: "Talleres de Movimiento en Comunidades" en el año 2013, el cual estaba enfocado en poblaciones de Limón, Liberia y Monteverde. Los coordinadores de DU a cargo fueron Eduardo Guerra, Mainor Gutiérrez y Gustavo Hernández, con la colaboración de miembros de la compañía en algunos talleres impartidos (Danza Universitaria, s.f., "Danza a la carta").

Los coordinadores desarrollaron de manera progresiva actividades, talleres y finalmente un espectáculo cada uno. De manera intencionada, DU dispuso de parte del elenco para aventurarse en compartir experiencias con el cuerpo y el movimiento, e inició todo un proceso de vinculación con comunidades donde la danza fue un objetivo común. De este proyecto se deriva: "Golfito baila: Talleres de movimientos en comunidades 2013-2014" de los estudiantes Leonela Solano, Fernanda Segura y Fabián Madriz.

ESCENA. Revista de las artes, 2021, Vol. 81, Núm. 1 (julio-diciembre), pp. 369-398 
COMUNIDANZA II: análisis en torno a la práctica artística entre danza,

Dossier comunidades y acción social

\section{Rutas de la danza: metodologías compartidas para los saberes del cuerpo (2014)}

Es una memoria teórica realizada por Verónica Monestel en el marco del curso de la Subcomisión Evaluadora de Proyectos de Extensión y Acción Social de CONARE (Consejo Nacional de Rectores, 2014). Este proceso se realizó con base en el proyecto "Juventud Creativa" (2011) y utilizó la Metodología de Sistematización de Experiencias propuesta por Óscar Jara, con el fin de alcanzar los objetivos de análisis del proyecto artístico a través del proceso e interpretación de las vivencias.

Rutas de la Danza5: metodologías compartidas para los saberes del cuerpo propone sistematizar contenidos de la metodología utilizada por los coordinadores-bailarines de Danza Universitaria: Iván Saballos, Evelyn Ureña, Elián López y Eduardo Guerra. Se enfocó primordialmente en la metodología planteada durante los talleres impartidos, con el propósito de mejorarla y fortalecerla. De este modo, se generó un espacio reflexivo que permitió, de manera más articulada y consciente, un análisis crítico basado en las prácticas.

El proceso de sistematización logró aprendizajes con ayuda del ejercicio crítico y reflexivo que, a su vez, se apoyó en un marco teórico afín al componente práctico de la danza, pero con recursos importantes para la introspección y generación de teoría sobre esas prácticas. Los cuatro miembros de la compañía responsables concluyeron que:

La sistematización de experiencias ayuda a aclarar los conceptos y caminos. Como facilitadores y artistas nos permitió aclarar concepciones que no teníamos teorizadas y sucedían solo desde lo intuitivo. Aclara todo el panorama de lo que se hizo. Poder trasladar una idea a lo físico. Se consigue tener el conocimiento de manera consciente. Ayuda a afirmar los modos intuitivos e imaginativos. Lo auténtico de ellos (Monestel, 2014, p. 30).

\footnotetext{
5 Ver el artículo “La danza como forma de conocimiento” de García (2016).
} 


\section{Sur (2015-2016)}

Golfito se convierte en una comunidad con la que se extiende el proyecto de talleres a un proceso creativo audiovisual, el cual brinda continuidad a un trabajo que inició en el 2013. "Sur"6 contó con la colaboración de Gustavo Hernández, Mainor Gutiérrez y de quienes participaron de los talleres iniciales del año 2013. Al igual que los proyectos anteriores, los profesionales de DU se adentraron en la comunidad por medio de la exploración de locaciones y del desarrollo material de movimiento con las intérpretes, el cual se reflejó no solo en la video-creación, sino a través de una exposición fotográfica y de un conversatorio de la Sede Rodrigo Facio de la Universidad de Costa Rica (Universidad de Costa Rica, 2016).

\section{Mi cuerpo, mi voz (2017)}

Se presenta como una iniciativa colaborativa del Departamento de Audición y Lenguaje del Centro Nacional de Educación Especial Fernando Centeno Güell y de Danza Universitaria. El desarrollo de esta propuesta permitió la realización de tres procesos diferentes: en primer lugar, la estimulación corporal de las personas participantes a través de talleres que les permitieran el desarrollo de habilidades físicas, comunicativas y expresivas; en segundo lugar, la realización y estreno de la obra El Ladrón de Diamantes, en el Teatro Nacional, como resultado de un proceso de creación artística junto a DU; finalmente, la realización del documental Baile en silencioㄱ (Cirotti, González \& Jiménez, 2012).

\section{Foros y conversatorios}

Los foros y conversatorios organizados por DU son otras modalidades que han integrado las actividades vinculadas a diferentes sectores, grupos y comunidades. Estos se han planteado como parte de procesos artísticos, colaboraciones con unidades académicas, sector independiente, artistas internacionales y profesionales en diferentes campos.

6 Esta producción audiovisual Danza Universitaria (2016) ,dirigida por Hernández, se encuentra disponible en https://www.youtube.com/watch?v=XKVd7HAqsgc

7 El documental se encuentra disponible en https://www.youtube.com/watch?v=M_Voxpi3Rfl\&t=12s

ESCENA. Revista de las artes, 2021, Vol. 81, Núm. 1 (julio-diciembre), pp. 369-398 
COMUNIDANZA II: análisis en torno a la práctica artística entre danza,

Dossier comunidades y acción social

Por medio de estas actividades la compañía ha ampliado su marco de vinculación inter e intrainstitucional. Además, ha reconocido la multiplicidad del conocimiento y el debate reflexivo en torno a las prácticas artísticas y su relación con otros campos, actores sociales, estéticas y culturas. Por tanto, ha sido importante para la generación de nuevos públicos y proyectos interdisciplinarios.

\section{Propuesta de creación de carrera: licenciatura en danza y corporeidad}

Esta nueva propuesta obedece a la intención del proyecto de Danza Universitaria de evolucionar hacia la creación de una carrera universitaria que profesionalice el quehacer de la danza contemporánea. Esta contempla tres aspectos:

una nueva concepción de la profesión dancística más allá de la puesta en escena, la legitimación de la labor formativa que desarrolla la Compañía Universitaria de Danza desde 1978, y el interés de la Escuela de Artes Musicales en ampliar y enriquecer su quehacer académico (Universidad de Costa Rica, 2019a, p. 9).

El proyecto se ha concebido desde áreas de la salud, la mediación educativa, la gestión cultural, la investigación teórica, el desarrollo humano comunitario y el referente contextual, como se muestra en la siguiente cita:

Así mismo, incluye la creación e interpretación escénica del danzante y la complejidad de sus procesos de creación y de aprendizaje. Toma en cuenta la inclusión y perspectiva de género, la contemplación de otras artes, la dimensión tecnológica, la sonoridad, el movimiento como acción humana comunicante y funcional; por último, concibe la música desde la corporeidad de cuerpos vividos, la singularidad, lo afín, diferente y complementario (Universidad de Costa Rica, 2019b, p. 75).

\section{Cartografía comunitaria 2011-2019}

El crecimiento de los vínculos comunitarios ha significado romper las formas tradicionales de trabajar, de hacer proyectos artísticos, organizarlos y planificarlos. Los sectores se han vuelto parte de un proceso de gestión bidimensional que estimula otras formas de entender la dinámica social. El incremento de poblaciones con las que se han establecido articulaciones integra una cartografía comunitaria (Imagen 2) que resume 
el tránsito por las siete provincias y algunos cantones y distritos del país. Esta dinámica se ha vuelto parte de la gestión e intención artística de la agrupación, materializada a través de proyectos sostenidos en el tiempo.

Imagen 2. Cartografía Comunitaria. Provincias y sectores del país visitados

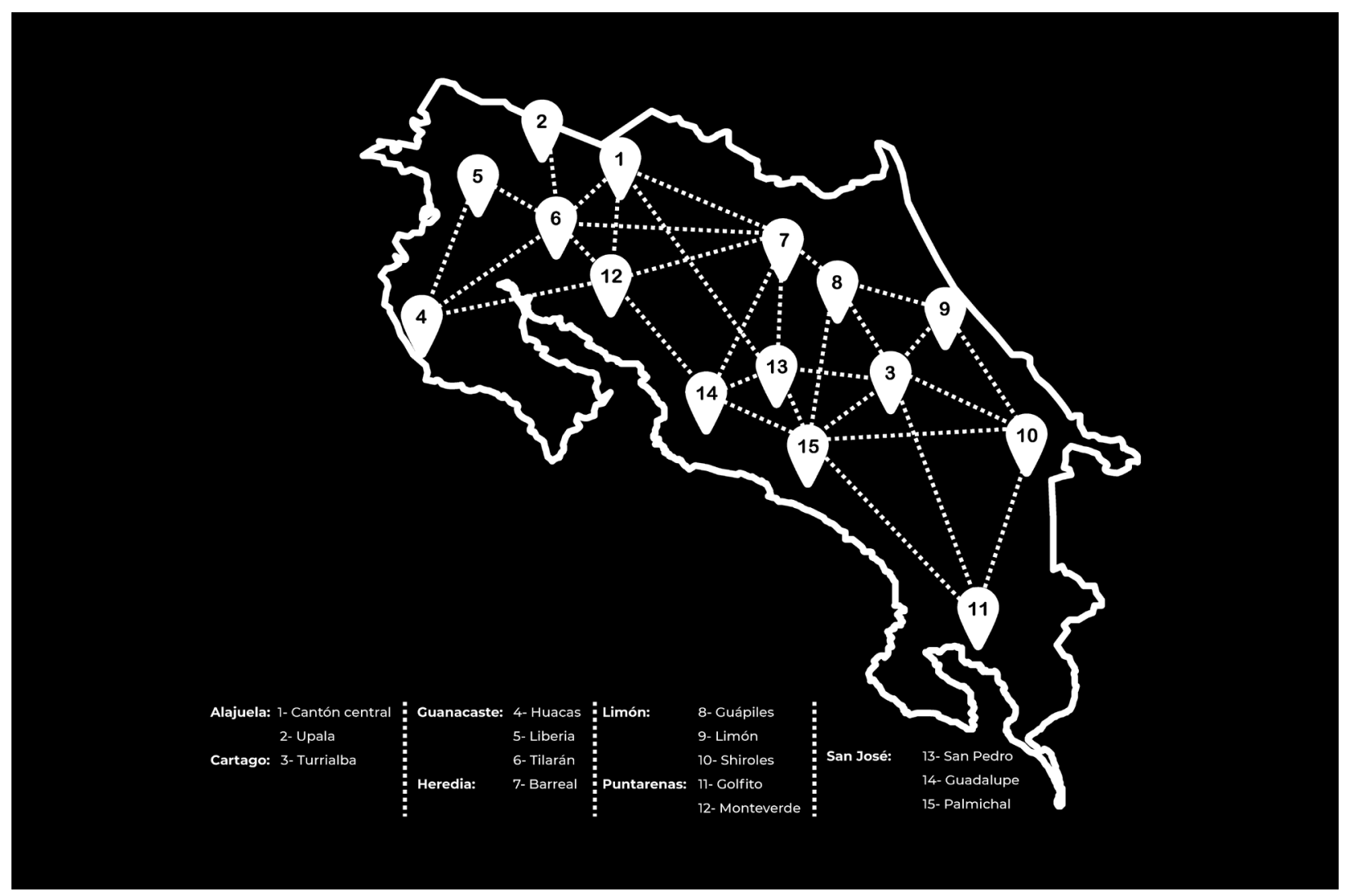

Fuente: Archivo Danza Universitaria (2020).

\section{Breve contexto latinoamericano}

Un referente importante es la Red Latinoamericana de Arte para Transformación Social (Ivercultura, 08 de enero de 2016). Esta reúne países como Argentina, Bolivia, Brasil, Chile, Perú, El Salvador, Honduras, Costa Rica, Guatemala y Uruguay. Dicha red abarca la práctica artística desde múltiples disciplinas y promueve los saberes del arte en ámbitos formales e informales. Sus experiencias han encontrado espacios para la visibilización de prácticas artísticas, donde el arte no solo funge como posibilidad para el cambio, sino que 
COMUNIDANZA II: análisis en torno a la práctica artística entre danza,

Dossier comunidades y acción social

apela intencionalmente a un contexto político, económico, social y educativo. Cada iniciativa propone aspectos relacionados con la realidad latinoamericana. Allí se reconocen las capacidades de sus habitantes y se abordan problemas de discriminación, derechos humanos, pobreza, abuso y adicciones, entre otros.

\section{Pensando la acción social}

\section{Comunicación}

La historia de la humanidad ha indagado ampliamente de qué manera los seres humanos estamos íntimamente ligados a procesos de comunicación, vinculación y relación, de los cuales depende el respectivo nivel de desarrollo alcanzado. Así como Erns Cassier propone en su libro Antropología filosófica (1967), tanto especies como organismos poseen un sistema emisor y efector, en menor o mayor grado, con el cual pueden transferir información y estar al tanto de su entorno. De igual manera, los humanos están provistos de un sistema comunicativo, en este caso mediado por símbolos y capaz de trascender el estado natural. Ello implicaría que la naturaleza humana nos hace un ser simbólico y comunicativo.

Esta característica, propia de los seres humanos, construye un camino donde el binomio símbolo-comunicación ha sido posible desde una compleja red de relaciones de orden genético, ambiental y social. El humano recurre al grupo, el clan o la comunidad, con el fin de hacerse de un lugar y construir una identidad simbólica y comunicativa. Este primer paso es un acto de supervivencia ante necesidades básicas que no siempre son cubiertas en el plano de la individualidad. Además, a nivel social, nos diferencia de otras especies el lenguaje con signos, códigos e imágenes que se transforman en un medio complejo de comunicación, mismo que incide directamente sobre la interacción (Stanford \& Roark, 1981).

\section{Comunidad}

La característica plural de la comunidad parte de la realidad diversa y multicultural que lleva implícita. Esta es una red compleja de fenómenos relacionados, con lugares, tiempos, sujetos y circunstancias particulares. Max Weber (1922) señala desde la sociología que: 
Llamamos comunidad a una relación social cuando y en la medida en que la actitud en la acción social -en el caso particular, por término medio o en el tipo puro- se inspira en el sentimiento subjetivo (afectivo o tradicional) de los partícipes de constituir un todo (Weber, 1922, p. 33).

Por su parte, en la obra Comunidad: en busca de seguridad en mundo hostil, Zigmunt Bauman (2003) nos habla de la comunidad elusiva, la cual remite a una sensación más allá del significado. El autor nos muestra el contraste entre lo cálido, seguro, solidario, confortable y acogedor de la comunidad (2003), así como la realidad de nuestro tiempo, donde esas características comunitarias se desvanecen en la individualidad, colocándola como un fenómeno de añoranza o un tipo de paraíso perdido, al cual se desea con todas las fuerzas (William, 2001, citado en Bauman, 2003). En este sentido, la percepción de lo que actualmente llamamos comunidad es parte de una estructura social compleja, llena de matices, dinámicas y procesos distintos, que no entran en un contenedor homologado de conductas sociales.

En resumen, por un lado, Weber (1922) nos plantea una comunidad que junto a otras permite el desarrollo personal y la libertad. Por otro lado, Montero (2004) la presenta como un encuentro transformador y de unión de las interacciones sociales, mientras que Bauman (2003) pone sobre la mesa una comunidad utópica y una realidad cercana a la individualidad y no a la cohesión social.

Estos principios abren un camino de conexiones, que hacen de la danza no solo una disciplina del arte, sino un contexto comunitario en sí mismo, un arte intencionalmente social. La comunidad es un fenómeno esencialmente comunicativo, razón por la que tanto la danza como la comunidad se asumen como constructos interrelacionados que comparten dinámicas procedimentales y experienciales, fruto de su propia naturaleza y realidad comunicantes. Son primordialmente movimiento y comunicación a todo nivel. Este proceso movilizador no es estandarizado, salta entre dinámicas propias que hacen de la experiencia un espacio único de relación.

La comunidad en la danza deviene de las experiencias como fuente de acción, pensamiento y conexión entre sujetos. Estas permiten visualizarlas como comunidades no utópicas, donde la pertenencia, el territorio, la cohesión e identificación pueden ser parte de su 
COMUNIDANZA II: análisis en torno a la práctica artística entre danza,

Dossier comunidades y acción social

estructura, más no lo que las define como tales. La danza parte de otros registros donde está claramente posicionado el cuerpo. Lo territorial deviene en cualquier espacio donde se generan las acciones y donde ese cuerpo subjetivo atraviesa una realidad propia y colectiva.

Una de las tantas experiencias de DU que ilustran lo anterior sucede con comunidades de adultos mayores (Imagen 3) que generan espacios de identificación personal y social en los diferentes contextos poblacionales, a partir de relaciones corporeizadas. Este espacio invita a compartir formas de expresión mediante las cuales se reconocen características particulares de cada sujeto y del grupo.

Imagen 3. Grupo adulto mayor. Sede Guanacaste, Universidad de Costa Rica

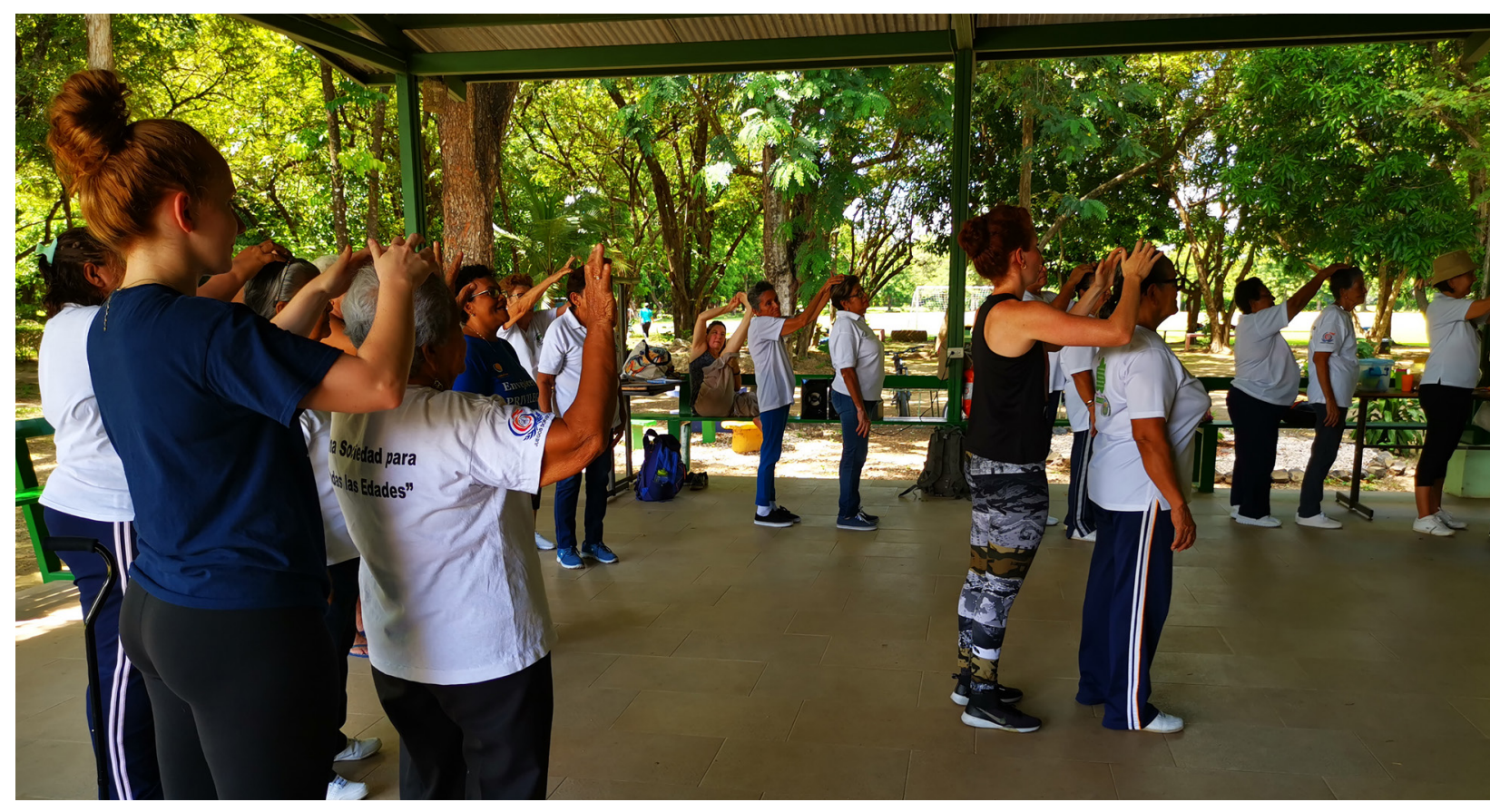

Fuente: Archivo Danza Universitaria.

La comunidad desde una perspectiva dancística, como afirma Weber (1922), es la unión de la acción social como conducta y -agrego- una conducta corporeizada con el movimiento danzado y simbólico. Montero (2004) también incorpora elementos afines, pues plantea que la comunidad en sí misma es un ente en movimiento, siempre en proceso de ser, en constante transformación, en la cual cumplen un papel determinante la identidad 
colectiva y la historia social que surge de la interacción. Estas características convergen con la danza, la cual invita a moverse y a generar movimientos en entornos inestables, diversos y particulares.

La coincidencia con Montero (2004) interesa en el entendido de que los procesos de interacción creados por relaciones humanas particulares son epicentro de experiencias, intercambio de saberes, reflexión, prueba y error. Allí, cada participante asume un rol individual y grupal; también utiliza el contexto, la diversidad expresiva y su propia experiencia de vida para alcanzar un objetivo común.

\section{El vínculo}

La noción del vínculo está permeada por múltiples enfoques que oscilan entre lo intrasubjetivo y lo intersubjetivo. En la década de los años cincuenta, el concepto toma relevancia con el suizo-argentino Enrique Pichon-Riviére (1980), quien establece la Teoría del vínculo, la cual genera una conexión con la práctica artística comunitaria. Picho-Riviére retoma el pensamiento freudiano y, como psicoanalista, recurre tanto a lo intrasubjetivo como a lo intersubjetivo. Para este investigador, el sujeto es creativo, activo y transformador de su contexto sociocultural; utiliza además el vínculo como forma de conectar con otros, a la vez que crea una estructura para sí mismo. Hablamos entonces del vínculo entendido desde una perspectiva social, donde es visto de forma bidireccional entre sujetos. El ser humano genera vínculos con el otro, por ende, una afectación en la constitución del sujeto.

Este enfoque, en parte, coincide también con lo que Freud establece como una diferencia entre la psicología individual y la psicología social. En su obra Psicología de las masas y análisis del yo (2004 [1920]), el autor claramente anuncia la perspectiva social a la que se hace referencia:

En la vida anímica del individuo, el otro cuenta con total regularidad, como modelo, como objeto, como auxiliar y como enemigo, y por eso desde el comienzo mismo la psicología individual es simultáneamente psicología social en ese sentido lato, pero enteramente legítimo (Freud, 2004, p. 67).

Ese componente de afectación entre sujetos es uno de los primeros enlaces reconocibles en el ámbito de la danza y sus diferentes áreas de acción. El vínculo juega un papel determinante en la construcción de subjetividades, pero también de aquellos procesos 
COMUNIDANZA II: análisis en torno a la práctica artística entre danza,

Dossier comunidades y acción social

y prácticas artísticas situadas en busca de expresividad y sentido. La comunicación, la comunidad y el vínculo son espacios interelacionados que permiten conocer y reconocer el propio desarrollo creativo.

Para la práctica artística, los procesos de creación colectiva permiten encuentros con otros para pensar-pensarse, construir futuros posibles en conjunto, basados en solidaridad, compromiso y transformación de la realidad (Bang \& Wajnerman, 2010). Van más allá, pues en la creación artística colectiva el sujeto construye espacios de resistencia y discursos contrahegemónicos al individualismo imperante, incidiendo directamente no solo en la transformación de los vínculos a lo interno de un grupo, sino hacia el resto de la comunidad (Bang \& Wajnerman, 2010).

\section{La acción social}

La influencia sociológica ha sido inevitable a la hora de hacer cualquier conexión con la acción social como fenómeno vivo entre los sujetos. Los postulados teóricos sobre este tema son de larga data, con visiones tanto divergentes como semejantes. La acción social es un fenómeno que ha transitado por el desarrollo mismo de las sociedades y su pensamiento individual y colectivo.

La acción social es un tipo de contenedor sistemático de esa comunicación entre sujetos, las comunidades que gestionan y los vínculos creados en el intercambio sociocultural. Desde el punto de vista de Weber (1922) existe una correlación entre sujetos, la sociedad y las conductas desencadenantes. La acción social como conducta demanda mirar y mirarse dentro de una estructura social y cultural que además es intencionada. Para la danza y su deliberado foco en lo cinético-corpóreo esta acción se materializa a través del movimiento, el cuerpo, un tiempo y espacio determinados. Los lugares, las ideas, las personas y los objetos son estímulos de la acción expresiva, desplazada y situada en cuerpos socializados, universales, polimórficos, polivalentes, complejos, motores, técnicos, expresivos, individuales y colectivos (García, 2005).

Todas las características implícitas en la esencia de las expresiones corporales y en la práctica de la danza entretejen la experiencia sensorial, cognitiva, emotiva y racional. Así, abrazan el entorno como espacio dador de motivaciones para la comunicación, el vínculo y la comunidad. Además, el evento perceptual existente puede desplegar idearios orientados a una transformación en el estado de las cosas, las personas y sus asociaciones.

ESCENA. Revista de las artes, 2021, Vol. 81, Núm. 1 (julio-diciembre), pp. 369-398 
Anthony Giddens advierte que: "Acción no es una combinación de actos: los actos están constituidos solo por un momento discursivo de atención a la duración de un vivenciar" (Giddens, 2006, p. 6). Este sociólogo establece, más bien, que la acción es un proceso dinámico y creativo que moviliza la reflexividad del individuo en el marco de una vida cotidiana rutinaria.

\section{La interacción y el cuerpo como acción social}

Todo ser vivo utiliza la interacción como forma de subsistencia y desarrollo, particularmente, el ser humano lo ha hecho desde lugares simbólicos con su entorno social. Este fenómeno relacional no sería posible sin un cuerpo a través de y en el cual se materialice la experiencia vivida y compartida junto a otro(s).

El cuerpo es además parte de ese sistema de símbolos generadores de lenguaje, gestualidad, expresión y emoción, que nos diferencia ya de otras especies a partir de la actividad psicofísica que produce a nivel individual y colectivo (Le Breton, 2018). El emisor y receptor existente en su naturaleza interaccional permite producir una constante red de sentido. El cuerpo es territorio con y desde el cual se construyen códigos de relación de un mundo personal y social, en un tiempo y espacio concretos. La interacción se construye en él desde el nacimiento, pero es hasta entradas algunas etapas de la vida que su corporeidad establece significados dentro de ese contexto social.

Buscamos el secreto perdido del cuerpo, hacer de él ya no el lugar de exclusión, sino el de la inclusión, para que deje de ser el interruptor que distingue al individuo, que lo separa de los demás, y devenga más bien el aglutinarse que lo une con los otros (Le Breton, 2018, p. 15).

El proyecto Mi cuerpo, mi voz (2017) integra elementos de interacción corporal a partir de una experiencia con niñas y niños sordos, donde el cuerpo construye sus propios códigos expresivos. Los participantes utilizan, como formas de comunicación entre pares y profesionales en danza, la vibración del sonido, la gestualidad, la observación y la repetición de acciones concretas, las cuales también son insumos creativos. La experiencia permite la inclusión de elementos individuales y colectivos, donde los niños y niñas aprenden a desenvolverse desde formas no tradicionales de expresión.

ESCENA. Revista de las artes, 2021, Vol. 81, Núm. 1 (julio-diciembre), pp. 369-398 
COMUNIDANZA II: análisis en torno a la práctica artística entre danza,

Dossier comunidades y acción social

Imagen 4. Proyecto Mi cuerpo, mi voz (2017) dirigido a niñas y niños sordos. Colaboración con el Departamento de Audición y Lenguaje del Centro Nacional de Educación Especial Fernando Centeno Güell y de Danza Universitaria

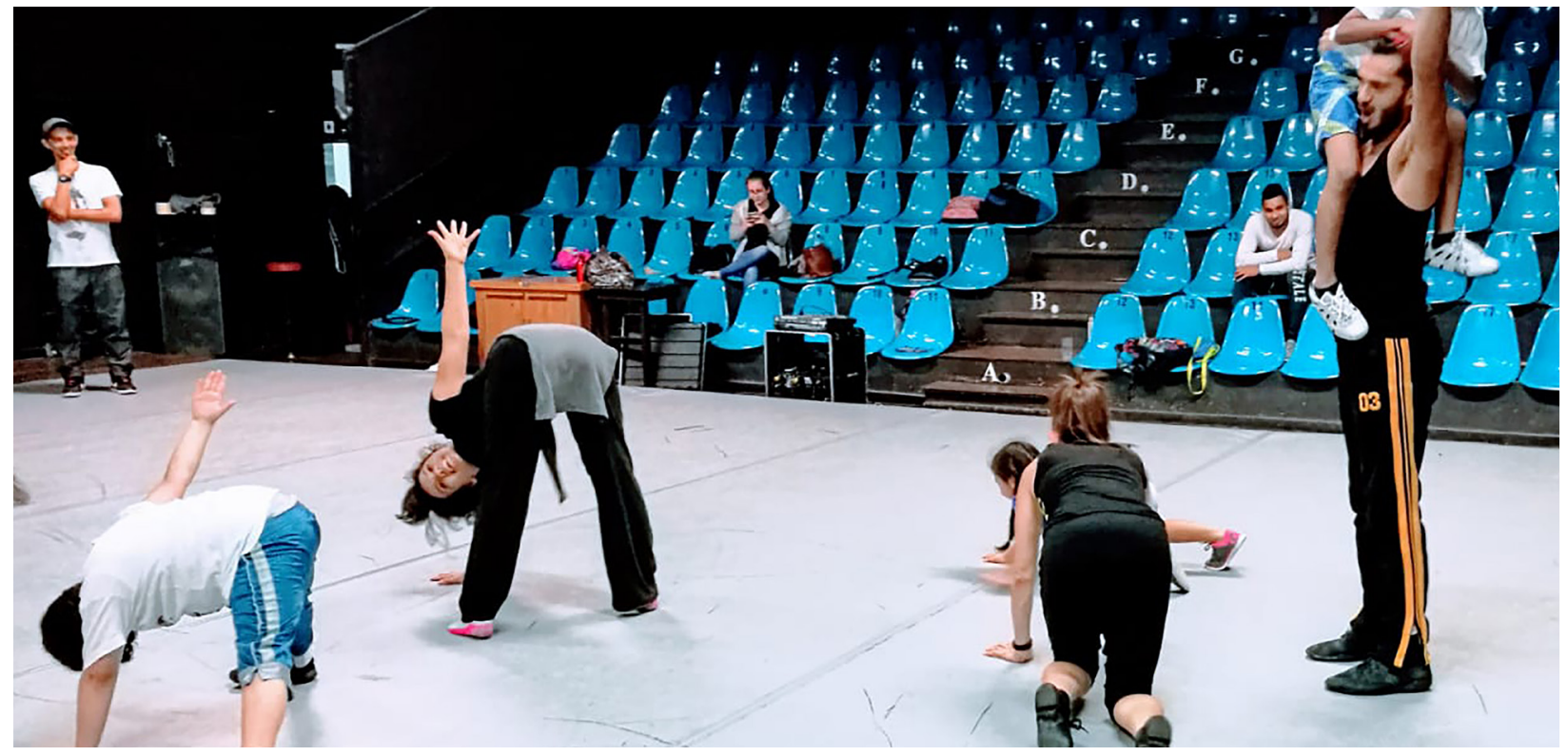

Fuente: Archivo Danza Universitaria.

Hablamos, entonces, de que el cuerpo trasciende el carácter biologista e instrumental en el que se le ha colocado para ser un constructo de orden sociológico sobre el cual muchos investigadores han planteado sus teorías. El contraste entre enfoques y teorías en torno al cuerpo es amplio; se ha movido entre una ambigüedad constante que va desde la mirada biologista y funcionalista hasta visiones más míticas e idealizadas. El cuerpo es transmisor de significados, de sentido y artífice de preguntas más que de certezas. Además, lo logra desde un sistema receptivo y expresivo donde la mediación sensorial reafirma sus relaciones.

Las prácticas artísticas de la danza devienen no solo de un espacio-tiempo determinado, sino que la experiencia del movimiento situado hace del cuerpo un constructo de identidad que problematiza la realidad. "Aquel denominado instrumento de la danza como cuerpo es a la vez el instrumento mediante el cual se vive la vida” (Graham, 1995 [1991], p. 30, citado en Mora, 2015, p. 124). Marta Graham visibiliza esta característica en el contexto de la danza moderna. A partir del desarrollo de la danza contemporánea, las técnicas 
y la diversidad de lenguajes esta se asume como cuerpo instrumental y sociocultural, a la vez que cuerpo donde se vive y expresa la vida. Es la suma de la experiencia y la existencia. Al respecto, Mora resume:

El cuerpo no solo es algo con lo que se expresa, no solo expresa algo que proviene de una experiencia subjetiva a través del movimiento, sirviéndose de él, sino que él mismo, en su materialidad y en el modo en que ha sido construido, expresa. No solo es un espacio habitado por un sujeto, sino que es un lugar vívido, un espacio experimentado, producto, productor de experiencias, representaciones y prácticas (Mora, 2015, p. 127).

\section{Naturaleza interactiva de la danza}

En la danza es imprescindible la interacción para que pueda ser vivida plenamente como experiencia significativa. Esta sucede en un espacio y tiempo concretos en constante intercambio de experiencias, sentimientos y sensaciones. Se trata de una presencia física inmediata, cara a cara y conjunta, desde códigos propios del lenguaje del cuerpo (no verbal). Al respecto, Stanford y Roark (1981) hablan de un lenguaje más allá que perfecciona, modifica y a veces sustituye las palabras entre las personas. Su naturaleza apela a una emotividad constante donde se generan, modifican o erradican conductas y formas de pensar (Monestel, 2014).

Por su parte, García (2005) va más lejos y propone diferentes dimensiones que reflejan el carácter múltiple desde el arte. Expresa que la danza es:

una actividad humana universal, pues se ha realizado en todas las épocas, espacios geográficos y es practicada por personas de ambos sexos y de todas las edades; motora, ya que utiliza el cuerpo humano como medio de expresión de ideas, emociones y sentimientos; polifórmica, porque se presenta en diferentes formas (arcaicas, clásicas, modernas...); polivalente, pues puede tener dimensiones artísticas, educativas, terapéuticas, de ocio; y compleja, ya que en ella interactúan factores biológicos, psicológicos, sociológicos, históricos, estéticos, además de ser simultáneamente expresión/técnica y actividad grupal/colectiva. Así mismo, Ruso habla de cuatro dimensiones que califica a la danza como educativa, de ocio, terapéutica, educativa y artística (García, 2005, p. 17). 
La danza es un espacio de encuentro e intercambio, de goce y simbolismo. Es comunicación y representación de aquello que se logra percibir, experimentar y transmitir con el movimiento corporal y lo encarnado de su vivencia. La danza, como expresión humana, es un arte entrelazado al cuerpo, al espacio y al mundo. Deviene posibilidades emotivas, culturales y lúdicas para crear comunicación y expresión en movimiento. De tal manera, desarrolla un saber corporal por cuanto con ella se descubre que todos los cuerpos tienen capacidades creativas particulares que pueden potenciarse y evolucionar.

Este tipo de existencia corporal con el movimiento se demarca en diversas situaciones creativas y modos de vivir la estética y el universo existencial del sujeto, el cual desarrolla una relación interior dinámica, intensa e intencionada, inmersa en voluntades y vivencias subjetivas que se codifican. Al mismo tiempo, su situación creativa sucede junto a vínculos, afectos, juegos trasversales con otros sujetos, lo que permite acuerdos intersubjetivos libres de transitarse. Existen trazos, huellas únicas y particulares, que llenan de sentido las relaciones humanas, artísticas y creativas, orientadas a la búsqueda de objetivos comunes. La danza también es un fenómeno que asume su práctica desde el lugar, la situación, pero sobre todo, desde su relación con la otredad. Hablamos de un fenómeno situado, un arte social, reflejo de una cultura, de formas de pensar, de sentir, de hablar y mirar.

Las características presentes en este arte diversifican los vínculos humanos. Suceden por medio de la manifestación cultural de sujetos implicados intencionalmente en la vida artística. Surgen de los ámbitos formales y profesionalizados, pero también de las relaciones con actores sociales y culturales informales de las comunidades, grupos organizados, gremios barriales, instituciones y colectivos, ya sea a nivel nacional, regional o internacional. Además, genera procesos de intercambio cultural con las llamadas comunidades geográficas, de igual manera con aquellas que no lo son.

\section{El componente educativo}

En las experiencias de los últimos 11 años con la comunidad, Danza Universitaria no ha dejado de lado el abordaje pedagógico y didáctico. El desarrollo de los diferentes proyectos incluye dentro de sus etapas: el intercambio de técnicas, disciplinas y géneros de danza con actividades expresivas, que llevan implícito procesos de enseñanzaaprendizaje entre pares. 
Es importante mencionar que parte de las comunidades con las que se han desarrollado dichos procesos han manifestado, por diferentes medios, su interés para llevar a cabo prácticas artísticas con el cuerpo y la danza, las cuales convocan a autoridades, miembros de la comunidad y artistas profesionales. En el camino han surgido inquietudes sobre mentadas experiencias educativas y su falta de análisis profundo en el contexto comunitario. Estas no pretenden ser un depósito unilateral de conocimiento desde el arte académico, culto o profesional, sino un proceso de intercambio de saberes, discusión, reflexión y, sobre todo, de fortalecimiento de habilidades y liderazgos de las propias comunidades.

En el VII Congreso Universitario, llevado a cabo en el año 2014, se presentó la ponencia "Lineamientos para una revisión del concepto y de la práctica de la Acción Social en la Universidad de Costa Rica" (Ochoa, Salom \& Solano, 2014), elaborada por profesionales y funcionarios de la Vicerrectoria de Acción Social, entre ellos: Luisa Ochoa Chaves, Roberto Salom Echeverría y Vania Solano Laclé. En ella se abordó el principio didáctico de la acción social como parte fundamental, la cual enfatiza el desarrollo de experiencias de enseñanza-aprendizaje con comunidades, ya que a partir de dicha interacción se aporta, entre otros aspectos, insumos para la construcción de teorías pedagógicas de aprendizaje.

En los últimos años, la implementación de nuevos postulados ha significado para DU repensar y cuestionar la práctica artística, así como la responsabilidad formativa de todo el elenco. También, ha supuesto la implementación de diferentes abordajes pedagógicos de los profesionales en danza, donde se han elaborado estrategias a priori, en razón del desconocimiento profundo de la comunidad por visitar, pero que terminan siendo marcados por los escenarios comunitarios. En estos espacios suceden sinergias que se dan de manera natural, espontánea, única y adaptativa con los participantes y su entorno.

El taller, por ejemplo, es una práctica artística fundamental en el proceso de intercambio de saberes y del reconocimiento de los sectores. En esos espacios la interacción abre paso al proceso creativo, a la exploración de sí mismo y lo que se logra como sujetos expresivos en movimiento. El taller facilita la autoregulación, así como el establecimiento de logros personales y colectivos, importantes para la misma dinámica de grupo.

La música, el espacio, el ritmo y el ambiente se vuelven insumos didácticos que transitan en la conformación de experiencias situadas, en las cuales emergen otras formas posibles de conexión pedagógica. Hablamos de un propósito didáctico que se gestiona con 
COMUNIDANZA II: análisis en torno a la práctica artística entre danza,

Dossier comunidades y acción social

la modalidad de talleres y no solo de espectáculos. En este sentido, podríamos decir que en esta práctica se establecen las primeras iniciativas de intencionalidad, de transformación individual y grupal, con una participación activa, directa y corporeizada de la población.

Inés Sanguinetti, artista argentina con gran trayectoria en la danza y el arte para la transformación social en Latinoamérica, atribuye al taller el lugar de la grupalidad donde se desarrolla la sensación de pertenencia, por medio de ejercicios que logran conexiones entre pares en minutos, cuerpos que se sienten parte del colectivo (Daza, 2012).

Imagen 5. Taller de baile popular, Colegio de Turrialba

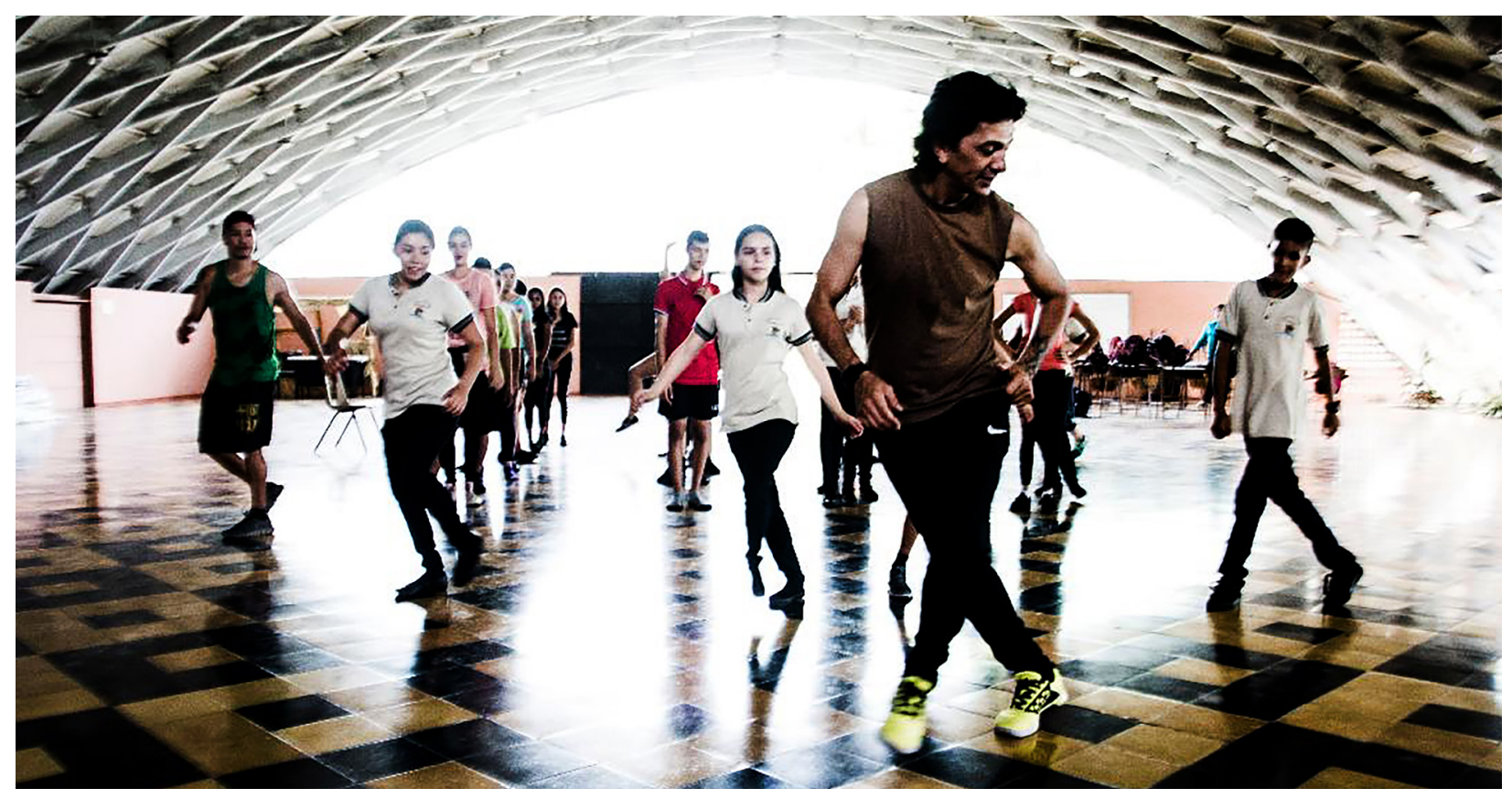

Fuente: Archivo Danza Universitaria.

Según Daza (2012), la danza genera aportes en la organización de lo emocional y también la ruptura de la disciplina social, la cual pone en movimiento el cuerpo desde otras lógicas, incluso antes de pensar y formular la palabra. Esta arista propone, desde la Fundación Crear Vale la Pena, que el sustento transformador de la renovación pedagógica implica una participación de los actores sociales con diferentes competencias y saberes. Los talleres proponen como renovación pedagógica la permanente mezcla de participantes principiantes, intermedios y avanzados. 


\section{Encuentros activos de participación}

El término diagnóstico es una herencia que las ciencias sociales toma del campo de la medicina. Esta última lo asume como una recolección y análisis de datos para evaluar un problema determinado, sobre el carácter de una enfermedad a partir de sus signos (Real Academia Española, 2020). No obstante, ese carácter de evaluación que anticipa una problemática específica se vuelve parte de la aversión que provoca, en el caso de la danza, pues el roce artístico y cultural no se genera solamente a partir de una problemática. Más bien, lo denominado problema, síntoma o signo de enfermedad puede tener connotaciones positivas, proyectivas e integradoras de un cambio personal y colectivo importante, donde el discurso de los sectores se vuelve un eje movilizador junto al arte.

En el documento sobre el Foro de Acción Social, llevado a cabo entre los años 2017-2018, en la Universidad de Costa Rica, el diagnóstico fue un tema relevante de discusión, precisamente por estar ausente en los proyectos de acción social y de los procesos. De ahí que se asuma tanto como vacío y práctica a nivel universitario. De hecho, no existen referentes a nivel de la Vicerrectoría de Acción Social sobre proyectos que lo hayan puesto en marcha.

Este plan es considerado de alta viabilidad e importancia para la gestión de proyectos de acción social según la comunidad universitaria. El manuscrito también hace referencia a la posibilidad de inscribir actividades y tiempos. Esos primeros vínculos comunitarios se pueden establecer mediante dichas posibilidades, con el fin de que sean inscritos como una etapa inicial previa a la formulación del proyecto. Así "permitiría contar con un espacio de unos seis meses para hacer un diagnóstico y para construir junto con las comunidades los proyectos que queremos desarrollar" (Universidad de Costa Rica, 2019b, p. 113).

Para las artes es fundamental recoconcer el camino recorrido por las ciencias sociales; de igual forma, es necesario un intercambio intencionado de sus recursos, pero estos deben construirse desde la práctica artística y el conocimiento de las artes. Según Aguilar y Ander-Egg (1995), el diagnóstico es un lugar posible, pero para su implementación es necesario el roce con otros enfoques y metodologías poco exploradas en la práctica artística de la danza en Costa Rica, tales como la educación popular, la Investigación Acción Participativa (IAP), el arte comunitario y la sistematización de experiencias. Su valor como sistemas educativos, metodológicos y de orientación emancipatoria de los pueblos latinoamericanos 
COMUNIDANZA II: análisis en torno a la práctica artística entre danza,

Dossier comunidades y acción social

marca un énfasis en la práctica como forma de conocimiento, pero no la limita a ello. Esa praxis se complementa con procesos teóricos que procuran partir de la acción, el aprender haciendo y la colaboración.

El término diagnóstico, desde una perspectiva de la danza, no promueve una empatía integral dado el referente médico tradicional con el que se le asocia, pues este último tiende a deshumanizarla. Al respecto, se propone hablar de encuentros activos de participación (con un carácter lúdico-artístico), una práctica menos conocida, la cual invita a dar un primer paso en la búsqueda de herramientas que permitan conocer a los miembros de la comunidad.

Está claro que los procesos de arte comunitario no deben responder a las necesidades de los agentes externos, pero la intencionalidad de realizar procesos que surjan de las comunidades exige un cambio en las formas en que estos agentes artísticos llegan a ellas. En algún punto, ese primer vínculo con los diferentes sectores requiere de una escucha anticipada de necesidades, antes que la preparación o incursión misma de talleres y procesos creativos a ciegas y ajenos a la realidad de los sectores.

Esto implica descentralizar no solo el espacio de creación de la danza, sino de ideas y liderazgos artísticos. Ese eje descentralizador no solamente se enfoca en una acción geográfica o sectorial, también es una fenómeno que otorga protagonismo y poder de decisión ante los actores externos. Además, mantiene a las comunidades abiertas y atentas a su crecimiento particular, pero no las aísla del entorno total. Así mismo, en la danza no se pretenden encuentros de acción participativa tan prolongados a la hora de reunir propuestas comunitarias previas, más bien, se propone un proceso corto y condensado que esté directamente ligado a la estructura de los proyectos. La sucesión de problemas y vacíos de organización, programación y procedimientos entorpecen y distan de ser prácticas artísticas realmente transformadoras, al no existir ese encuentro previo con la comunidad. Se plantea como una necesidad que, lejos de ser simplemente un dato duro y desconectado de la realidad específica, proporcione una visión clara y coherente.

De esa forma, la puesta en práctica de encuentros para la acción puede ser un cambio multinivel, donde DU incorpore su acervo artístico y genere interacciones más profundas con otros sectores y áreas de conocimiento, también como una posibilidad para emprender otras formas de entender los contextos comunitarios. Así, el surgimiento de metodologías 
y guías funcionales desde la danza emergen como una posibilidad para crear sistemas abiertos de interrelación, que permitan compartir la diversidad existente, lejos de una mirada tecnocrática que escuche la voz local, todo ello sin caer en la estandarización.

\section{Conclusiones}

Los pilares fundacionales de las acciones comunitarias, en los últimos ocho años, parten del hacer-acción como epicentro y potencialidad de cambio. Así mismo, la comunicación, el vínculo, la interacción y el aprendizaje son constantes necesarias en la experiencia de ese sujeto corposintiente y pensante, que abre espacio a su propia transformación. En ese sentido, la acción social que se propone desde Danza Universitaria (DU) es un contenedor sistemático entre sujetos con conductas preconcebidas que despliegan su función a través de la acción cinético-corpórea-danzada. Ella entrelaza la experiencia sensorial, cognitiva, emotiva y racional. Es una acción orientada a la transformación del estado de las cosas, las personas y sus asociaciones; un espacio para la creatividad, el descubrimiento, la inclusión y la toma de decisiones.

La relación entre danza y comunidades es simultáneamente pedagógica, contiene estretegias didácticas orientadas a procesos emancipatorios de los grupos sociales y a comunidades participantes; aprendizajes entre pares, orientados al hacer, al proceso y al constante intercambio de saberes. DU sigue in situ propósitos didácticos propios de la acción social, donde el taller, el proceso creativo de obras, la clase maestra, el conversatorio, el documental y la sistematización de metodologías son estrategias para la cohesión, la escucha, la observación, la descentralización de la práctica artística y la autonomía.

Los hallazgos incluyen el reconocimiento de acciones artísticas comunitarias como redes complejas multifactoriales, con un alto componente comunicativo, de vínculo e interacción. DU propone prácticas artísticas situadas en búsqueda de sentido para pensar-pensarse, sentir-sentirse. Danzar se comprende como un espacio de resitencia ante sistemas hegemónicos de creación, formación y desarrollo. Esta acción deviene de la atención a un sistema de símbolos del cuerpo generadores de lenguaje y movimiento, de la emoción y los sentidos como facilitadores de interacción social, y del cuerpo como identidad, suma de experiencia y existencia.

La ruta trazada, entre el 2011-2019, ha permitido identificar aspectos fundamentales para el desarrollo pertinente de las prácticas artísticas en las comunidades, por ejemplo, aquellos que parten de lo creativo, pero que necesitan de lo institucional y estructural para 
COMUNIDANZA II: análisis en torno a la práctica artística entre danza,

Dossier comunidades y acción social

llevarse a cabo. En este sentido, los encuentros de acción participativa encajan más que el denominado diagnóstico y se proponen como opciones alternativas para los actores sociales y la propia comunidad universitaria.

Los encuentros para la acción en DU se plantean como un conocer a través de y por medio de; sobre todo, como un conocer con. También, se proponen como una escucha anticipada de carácter lúdico y creativo, centrada en la acción, la construcción de nuevas metodologías de mediación y el desarrollo comunitario inclusivo y descentralizado. Se identifican metodologías regionales desde la Investigación Acción Participativa (IAP), el arte comunitario, la educación popular y la sistematización de experiencias, con antecedentes importantes a nivel latinoamericano. Sus enfoques surgen de un alto componente práctico, en interacción y armonía con la teoría.

Finalmente, se hace necesario la construcción de una agenda comunitaria para el estudio de los diferentes contextos de participación, así mismo, establecer procesos de sistematización como parte de las etapas de los proyectos y no como fenómenos aislados. Además, se requiere de un fortalecimiento de la acción pedagógica y formativa para la creación de vínculos comunitarios, traducido en mejores capacitaciones e intercambio con otras áreas de conocimiento. A este respecto, la posibilidad de integrar comisiones interdisciplinarias con profesionales universitarios y comunidades puede ayudar a mejorar la práctica comunitaria de la agrupación y su ruta orientada a procesos artísticos autogestionados, dialógicos y autoregulados de y con las comunidades.

\section{Referencias}

Aguilar, M. J., \& Ander, E. (1995). Diagnóstico Social. México: Lumen.

Ávila, M. (2008). Trazos Vitales 1978-2008. San José: Editorama S.A.

Bang, C., \& Wajnerman, C. (2010). Arte y transformación social: La importancia de la creación colectiva en intervenciones comunitarias. Revista Argentina de Psicología, 48, 89103. Recuperado de http://www.psi.uba.ar/academica/carrerasdegrado/psicologia/sitios_catedras/obligatorias/066_salud2/material/publicaciones/arte_y_transformacion.pdf

Bauman, Z. (2003). Comunidad: en busca de seguridad en mundo hostil. Madrid: Siglo XXI.

Cassier, E. (1967). Antropología Filosófica. México: Fondo de Cultura Económica.

ESCENA. Revista de las artes, 2021, Vol. 81, Núm. 1 (julio-diciembre), pp. 369-398 
Cirotti, P. (Director), González, H. (Productora), \& Jiménez, M. (Productora). (2012). Baile en silencio [Video]. Costa Rica: Vicerrectoría de Acción Social de la Universidad de Costa Rica

Cirotti, P. (Director), Camacho, D. (Productora), \& Monestel, V. (Productora). (2012). Comunidanza [Película]. Costa Rica: Vicerrectoría de Acción Social de la Universidad de Costa Rica.

Danza Universitaria. (15 de junio 2016). Videodanza Sur. [Video]. Recuperado de https:// www.youtube.com/watch?v=XKVd7HAqsgc

Danza Universitaria. (s.f.). Comunidanza.DanzaU. Recuperado de https://danzau.ucr.ac.cr/ comunidanza

Danza Universitaria. (s.f.). Juventud creactiva. DanzaU. https://danzau.ucr.ac.cr/juventud_ creativa

Danza Universitaria. (s.f.). Danza a la carta. DanzaU. https://danzau.ucr.ac.cr/juventud_creativa

Daza, D. (2012). Arte y transformación social: entrevistas a referentes. Recuperado de https://www.academia.edu/42759358/Arte_y_transformaci\%C3\%B3n_social_entrevistas_a_referentes

Freud, S. (2004). Más allá del principio del placer. Obras Completas (Vol. 18) [1920]. Buenas Aires: Amorrortu.

García, H. (2005). La danza en la escuela. España: INDE.

García. G. (19 de octubre de 2016). La danza como forma de conocimiento. Portal de Acción Social de la Universidad de Costa Rica. [Página web]. Recuperado de https:// accionsocial.ucr.ac.cr/noticias/la-danza-como-forma-de-conocimiento

Giddens, A. (2006). La constitución de la sociedad: bases para la teoría de la la estructuración. Buenos Aires-Madrid: Amorrortu.

Iverculturaviva (08 de enero de 2016). Red Latinoamericana de Arte y Transformación Social: 15 proposiciones para el debate. Recuperado de https://iberculturaviva.org/red-latinoamericana-de-arte-y-transformacion-social-15-proposiciones-para-el-debate/?lang=es

Le Breton, D. (2018). La Sociología del Cuerpo. España: Siruela, S A. 
COMUNIDANZA II: análisis en torno a la práctica artística entre danza,

Dossier comunidades y acción social

Macias, Z. (2009). El poder silencioso de la experiencia corporal en la danza contemporánea. Bilbao: Artezblai.

Monestel, V. (2014). Rutas de la danza: metodologías compartidads para los saberes del cuerpo. San José, Costa Rica: Universidad de Costa Rica.

Montero, M. (2004). Introducción a la Psicología Comunitaria. Desarrollo, conceptos y procesos. Argentina: Paidós.

Mora, A. S. (2015). El cuerpo como medio de expresión y como instrumento de trabajo:dualismos persistentes en el mundo de la danza. Cuadernos de Música, Artes Visuales y Artes Escénicas, 10(1), 115-128. Recuperado de https://dialnet.unirioja.es/servlet/articulo?codigo $=5854995$

Ochoa, L., Salom, R., \& Solano, V. (julio, 2014). Lineamientos para una revisión del concepto y de la práctica de la Acción Social en la Universidad de Costa Rica. En V Congreso Universitario de la Universidad de Costa Rica. San José.

Pichon-Riviére, E. (1980). Teoría del Vínculo. Argentina: Nueva Visión SAIC.

Real Academia Española. (2020). Diagnóstico. En Diccionario de la lengua española. Recuperado de https://dle.rae.es/contenido/actualizaci\%C3\%B3n-2020

Stanford, G., \& Roark, A. E. (1981). Interacción humana en la educación. México: Diana.

Universidad de Costa Rica. (2005). Estatuto Orgánico de la Universidad de Costa Rica. Recuperado de: https://www.cu.ucr.ac.cr/estatuto-organico.html

Universidad de Costa Rica. (2019a). Propuesta de creación de carrera para la Licenciatura en Danza y Corporeidad. (Programa inédito).

Universidad de Costa Rica. (2019b). Aportes del Foro de Acción Social. Sistematiación de la experiencia. San José: Vicerrectoría de Acción Social de la Universidad de Costa Rica. Recuperado de http://www.kerwa.ucr.ac.cr/bitstream/handle/10669/79151/sistematizacion_del_foro_de_accion_social.pdf?sequence=1\&isAllowed=y

Universidad de Costa Rica. (2020). Políticas de la Universidad de Costa Rica 2021-2025. Recuperado de: https://www.cu.ucr.ac.cr/uploads/tx_ucruniversitycouncildatabases/ normative/politicas_institucionales_2021-2025.pdf

Weber, M. (1922). Economía y sociedad. México: Fondo de Cultura Económica.

ESCENA. Revista de las artes, 2021, Vol. 81, Núm. 1 (julio-diciembre), pp. 369-398 